\title{
EXPLORING THE ROLE OF GENETIC ALGORITHMS AND ARTIFICIAL NEURAL NETWORKS FOR INTERPOLATION OF ELEVATION IN GEOINFORMATION MODELS
}

\author{
H. Bagheri ${ }^{\text {a }}$, S. Y. Sadjadi ${ }^{\text {a. } *, \text { S. Sadeghian }}{ }^{\text {b }}$ \\ ${ }^{a}$ Dept. of Geomatics Engineering, School of Civil Engineering, University of Tafresh, Tafresh, Iran \\ hosseinbagheri1366@yahoo.com \\ y_sadjadi@yahoo.com \\ ${ }^{\mathrm{b}}$ Geomatics College of National Cartographic Centre, Tehran, Iran
}

Commission VI, WG VI/4

KEY WORDS: DEM, DTM, ANN, IDW, AI, GA, Interpolation, Elevations, Optimisation, Height

\begin{abstract}
:
One of the most significant tools to study many engineering projects is three-dimensional modelling of the Earth that has many applications in the Geospatial Information System (GIS), e.g. creating Digital Train Modelling (DTM). DTM has numerous applications in the fields of sciences, engineering, design and various project administrations. One of the most significant events in DTM technique is the interpolation of elevation to create a continuous surface. There are several methods for interpolation, which have shown many results due to the environmental conditions and input data. The usual methods of interpolation used in this study along with Genetic Algorithms (GA) have been optimised and consisting of polynomials and the Inverse Distance Weighting (IDW) method. In this paper, the Artificial Intelligent (AI) techniques such as GA and Neural Networks (NN) are used on the samples to optimise the interpolation methods and production of Digital Elevation Model (DEM). The aim of entire interpolation methods is to evaluate the accuracy of interpolation methods. Universal interpolation occurs in the entire neighbouring regions can be suggested for larger regions, which can be divided into smaller regions.

The results obtained from applying GA and ANN individually, will be compared with the typical method of interpolation for creation of elevations. The resulting had performed that AI methods have a high potential in the interpolation of elevations. Using artificial networks algorithms for the interpolation and optimisation based on the IDW method with GA could be estimated the high precise
\end{abstract} elevations.

\section{INTRODUCTION}

Maximum Three-dimensional modelling of the Earth is one of the most important tools for studying in various fields of geology, meteorology, civil engineering, environmental engineering, and numerous engineering projects that have many applications in the Geospatial Information System (GIS) [37][40][41]. GIS can generally be used to create the Digital Train Modelling (DTM) to display topography and synthetic changes and all environmental parameters such as temperature, air pollution, etc. [1][6]. One of the most significant parameters in GIS is the topography elevation of the Earth, which can be visualised in 3D digital form to represent the Digital Elevation Model (DEM) [2]. In other words, DEM continuously differentiates the surface elevation of the Earth, which is directly proportional to the plane position $(\mathrm{x}, \mathrm{y})$ [2][4][5]. Initially, 3D models were created physically from plastic, sand, clay, etc. [6]. Today, however, computers are used to display the Earths' continuous surfaces in a digital form [7].

One of the most important issues in the field of digital modelling is to generate the DEM with high quality and precision and keeping minimum costs. To estimate a continuous surface, due to the limited number of samples and the necessity of reproducing altitude points, the mathematical interpolation functions are used to estimate the elevation of midpoints [8]. Interpolation methods are used to determine unknown altitudes of midpoints from the samples and as a result, the coordinated points are reproduced and the digitally formed Earths' continuous surfaces can be visualised. Since any interpolation has mainly errors, those errors can be expanded through the calculations and processes. The results from interpolation are achieved and the Standard Deviation (SD) of the facts is not acceptable. Such errors transfer inaccurate assessments in the executable projects and convey the financial losses and even their life threatening results [9][10]. Therefore, one of the challenges in this method is to find an appropriate way in which the data source not only consists of accuracy and distribution of sample points but also, contains geomorphological characteristic of the Earth's Surface. The method in question for interpolation and the estimation of the middle points' height, will affect the quality and the accuracy of DEM [11][12].

Numerous methods for the interpolation have been proposed [13][14][15], which shows different results influenced by the environment's conditions and data input. Usually, the optimal method of interpolation depends on the Root Mean Square Error (RMSE) of the output. In most studies the comparison of interpolation methods and the selection of the optimal methods are used to achieve higher accuracy [16][17][18][19][42][43]. In this paper, AI techniques such as NN and GA were examined to optimise the interpolation methods and the creation of DEM on the samples. At the end, the results of the estimated heights from the intelligent techniques and the usual methods of interpolation are compared. 


\section{ARTIFICIAL NEURAL NETWORKS}

Artificial Neural Networks (ANN) is moulded based either on the performance of the human brain and its functionality or its actions can be interpreted according to the human conduct. Investigations show that this network has the ability of learning, reminding, forgetting, concluding, pattern-recognition, classification of information and many other brain functions [20]. NN is essentially made up of simple processing units called neurons [21]. ANN structures are in the form of layers, which consists of input layer, output layer and one or more intermediate layers. Each layer contains several neurons that are connected by a network, which has different weights. Based on how the nodes are connected to each other, $\mathrm{NN}$ are divided into two groups; ANN feed forward and feedback NN. In feed forward input, to produce the output, neurons must be used as the pathway. A feed forward $\mathrm{NN}$ is known as perceptron. Perceptron ANN is one of the most important and widely used aspects in diagnosis classification model [22]. Perceptron can be single-layered or multi-layered. The difference between single-layer and multi-layer perceptron is that there are one or more hidden layers existing between the input and the output layer. The task of these hidden layers is to extract the non-linear relationships from the input layer presented to them.

The two main steps that exist in the application of $\mathrm{NN}$ are; learning and recall. The aim of $\mathrm{NN}$ learning is finding the optimal weights of neuron connections, which is achieved by the recursive method [23]. Generally, the error back propagation learning rules are used to train the multi-layer perceptron NN. The law of error propagation is composed of two main routes; the first route is called way-in path, where the input vector affects the Multi-Layer Perception (MLP) network and impacts on the output layers through the intermediate layer. The output vector of the output layer is the actual response of the MLP network. In this way, the network parameters are fixed and unchanged. The second route is called the come-back path. In the come-back path, unlike the way-in path, the MLP network parameters can be changed and adjusted. This adjustment is consistent with the error correcting rule. The error signal at the output layer of the network is formed. Error vector is equal to the difference between the desired response and the actual response of the network. In the come-back path, the calculated error values are distributed in the entire network through the network layers. In this repetitive process, the corrected parameter weights are calculated and will be added to the previous weights and hence modified to prepare for implementation in the network [24]. In this algorithm, the network weights are based on the gradient method and the error signals are corrected and adjusted. Back propagation is used for explaining the correction of network behaviour, which is opposite to the weight communication between synapses [24]

\section{GENETIC ALGORITHMS}

In 1960, Rechenberg presented the basic idea of evolutionary algorithms, where GA can be derived from. This is, in fact, a computerised search method, which is based on the optimisation algorithms, genes and chromosomes, founded in Michigan University by Professor Holland [25] and then further developed [26].

In this algorithm, due to being derived from nature, stochastic search processes are used for optimisation and learning problems [27]. In nature, chromosome combinations will produce better generation. Among these mutations occurring within the chromosomes it may improve the next generation. GA solves these problems by using this concept [28].
Overall operations of this algorithm are; fitting, selecting, combining and mutating [29]. In the algorithm process, an initial population of chromosomes is selected for the creation of a new and possibly better generation. Each chromosome has various arrays that should be optimised. After creating the initial population of merit (cost consumption) for each chromosome in the population the calculation is based on the objective function. The major parts of the chromosomes that are too costly are left behind and the chromosomes that are sufficiently cost for evaluation are to be kept to produce the next generation of children. Among them, there are a number of elite chromosomes, which are considered to be low-cost, are chosen and remain untouched for the next generation. To determine the number of chromosomes needed to integrate, parents are selected to produce offspring. Two chromosomes are selected as parents when they are combined. Sometimes randomly genes are changed; a mutation occurs and enables the algorithm to search for a wider area. In other words, new generation can be created by reproductive processes of combining gene and mutation. This process must be repeated many times to achieve convergence and create an optimal solution [30].

\section{HEIGHT INTERPOLATION METHODS}

The main purpose of using the known point height interpolation is to determine the heights of the unknown's middle points. In 2004, Yang examined different methods for interpolation according to the accuracy and applicability by using Surfer 8.0 software [19]. These methods can be divided into different criteria [2]. For example, interpolation methods based on surface coverage divided into local and global criteria. In the global methods, the height of all control points are used to estimate the heights for the unknown points, but in the local methods, calculation of unknown points' heights are derived from the height of the neighbours' points. In this research, the different methods of interpolation are used to estimate the heights at the unknown points within the local methods, which are explained in the following sections:

\subsection{Inverse Distance Weighting Method}

In Inverse Distance Weighting (IDW) method, the height information of neighbouring points according to the distance of unknown points and used based of weight. Weight is a function of the distance from the unknown point and hence closer points have higher weights. For height calculation, the following equation is used:

$$
z=\frac{\sum_{i=1}^{n} \frac{z_{i}}{d_{i}^{p}}}{\sum_{i=1}^{n} \frac{1}{d_{i}^{p}}}
$$

In this equation, $p$ is the speed reducer weight control rate according to distance, where it is equal to $2, d_{i}$ is the distance from unknown point to well-known point and $z_{i}$ represents the height of point $i[31][41][44]$.

\subsection{Polynomial Method}

This method approximates the surface using polynomial terms plain elements $\mathrm{x}, \mathrm{y}$ in the form of $\mathrm{z}=\mathrm{f}(\mathrm{x}, \mathrm{y})$. The $n$ power of this polynomial equation is: 


$$
z=\sum_{i=0}^{n} \sum_{j=0}^{n} a_{i j} x^{i} y^{j}
$$

Where $x, y$ turned parts and plain components of known points and $a_{i j}$ are polynomial coefficients, which are determined using the know elevation values in the sample points and are obtained by least squares portion.

\subsection{Kriging Method}

Kriging method was introduced by Matheron in 1963 [32], based on the Krige variables theory zone [33]. This method is estimated based on a weighted moving average due to that the Kriging method of interpolation considers both criterions of distance and the changing of points' elevation. It is the best unbiased linear Vary-gram of weights with the minimal estimation of variance. This means that the difference between actual and estimated values is minimal. In the Kriging method, there are numerous techniques for valuing the height values, which normally are divided into two different ways; ordinary Kriging and general Kriging. The ordinary Kriging is calculated based on the following equation:

$$
z(x, y)=\sum_{i=1}^{n} \lambda_{i} z\left(x_{i}, y_{i}\right)
$$

Where $\mathrm{z}(\mathrm{x}, \mathrm{y})$ is the height estimated at unknown point, $\mathrm{z}\left(\mathrm{x}_{\mathrm{i}}, \mathrm{y}_{\mathrm{i}}\right)$ is the height of sample point $i$ and $\lambda_{\mathrm{i}}$ is the weight of point $i$.

For the estimation of the weight, various Vary-grams are used, such as; linear, exponential, Gaussian and spherical. General Kriging method is also the combination of ordinary Kriging with local process. The local process can be defined in two ways; linear trend and quadratic.

\subsection{Nearest Neighbour Method}

In the nearest neighbour method, the nearest point to the unknown neighbour is selected and its height is assumed based on the height of the unknown point. This method is an appropriate way if the data is taken based on a regular network and matching with the grid lines.

\subsection{Natural Neighbour Method}

Natural neighbour method was developed in 1980 by Sibson [35]. This method is based on Voronoi Pattern for a set of separated points. Voronoi Pattern is a diagram, which is dividing space into a number of regions. This method has more advantage compared with the nearest neighbour's method such as its ability to create a surface that is relatively smooth. This method is based on the following function [36]:

$$
z(x, y)=\sum_{i=1}^{n} \lambda_{i} z\left(x_{i}, y_{i}\right)
$$

Where $\mathrm{z}(\mathrm{x}, \mathrm{y})$ is the estimated height at unknown point, $z$ (xi, yi) is height of sample point $i$ and $\lambda i$ is weight of sample $i$ followed by the area enclosed by any parts of the unknown sample point.

\subsection{Triangulation Method}

This method deals with the linear interpolation elevations based on Delaunay triangulation [45].

Delaunay triangles are formed on raw points, which have the following features;
- The three corners of a triangle should not be on a curve.

- Two corners of a triangle can be on a curve, but the third corner must be on a separate curve.

- If a circle passes through the three corners of particular triangle, then it must not pass through the corresponding triangle's corner, which has a common side.

After the surface reconstruction with Delaunay triangles, the unknown height can be determined. Each surface equation of a triangle can be specified as follows;

$$
z=a x+b y+d
$$

Thus, the height of any point within this level would be:

$$
z_{c l}=a x_{c}+b y_{l}+d
$$

The coefficients $a, b$ and $d$ are calculated through the least squares method using the height of the elevation of the triangle's corners.

\section{DATA ASSESSMENT AND EVALUATION CRITERIA}

In order to evaluate smart and ordinary interpolation methods, two parts are commonly used. Part one is the existing software AutoCAD Civil 2D Land Desktop 2009 and part two is the acquiring data for mapping 1:2000 in Port Khamir, which is located in Hormozgan State, south of Iran. In both parts, numbers of points are used as the control points and two points are considered as the checkpoints. The points in both parts are shown in the Tables 1 and 2. Using control points and interpolation methods, the heights of the checkpoints (1) and (2) are obtained and it is compared with the actual height. Finally, the extent of errors that exist in the calculated elevations through standard interpolation methods can be determined by using RMSE rate. The measurement of RMSE can be expressed as follows:

$$
R M S E=\sqrt{\frac{\sum_{i=1}^{n}\left(z_{\text {comp }}-z_{\text {actual }}\right)^{2}}{n-1}}
$$

Where, $Z_{\text {comp }}$ is calculated height values and $Z_{\text {actual }}$ is actual checkpoint height.

Table 1: Area Profile 1

\begin{tabular}{|c|c|c|c|c|}
\hline $\begin{array}{c}\text { Elevation } \\
\text { Changes } \\
\text { (m) }\end{array}$ & $\begin{array}{c}\text { No. of } \\
\text { Control } \\
\text { Points }\end{array}$ & $\begin{array}{c}\text { No. of } \\
\text { Checkp } \\
\text { oint (1) }\end{array}$ & $\begin{array}{c}\text { No. of } \\
\text { Check } \\
\text { point } \\
\text { (1) }\end{array}$ & $\begin{array}{c}\text { Regional } \\
\text { Dimensions }\end{array}$ \\
\hline 16 & 123 & 28 & 26 & $250 \times 275$ \\
\hline
\end{tabular}

Table 2: Area Profile 2

\begin{tabular}{|c|c|c|c|c|}
\hline $\begin{array}{c}\text { Elevation } \\
\text { Changes } \\
\text { (m) }\end{array}$ & $\begin{array}{c}\text { No. of } \\
\text { Control } \\
\text { Points }\end{array}$ & $\begin{array}{c}\text { No. of } \\
\text { Checkp } \\
\text { oint (1) }\end{array}$ & $\begin{array}{c}\text { No. of } \\
\text { Check } \\
\text { point } \\
\text { (1) }\end{array}$ & $\begin{array}{c}\text { Regional } \\
\text { Dimensions }\end{array}$ \\
\hline 6 & 75 & 18 & 18 & $450 \times 300$ \\
\hline
\end{tabular}

\section{USING NEURAL NETWORKS IN HEIGHTS INTERPOLATION}

Interpolation of elevations based on ANN uses the Perceptron network, which consists of three layers; an input layer, an intermediate layer and an output layer. Structure and network topology is shown in Figure 1. Two neurons in the input layer are components of $\mathrm{x}$ and $\mathrm{y}$ and the output layer of neuron is 
component of z. Training is based on the gradient method. In the network learning process in both data points for training and a set of checkpoints; checkpoint (1) are areas of validation and checkpoint (2) is the independent checkpoint, these are used for testing and evaluating the precision interpolation networks. The error signal based on the RMSE is created and the sum of weight is used to achieve the minimum RMSE.

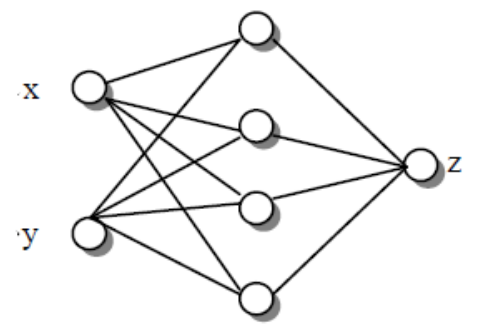

Figure 1: Network Perceptron with a Hidden Layer for the Interpolation Heights

\section{USING GENETIC ALGORITHMS IN HEIGHTS INTERPOLATION}

Unlike NN that is able to create a network for elevation interpolation method of genetic algorithm optimisation routine can only be used for interpolation. The usual methods of interpolation used in this study along with GA have been optimised and consisting of polynomials and the inverse distance weighting method, which will be described below. Due to this comparison, the Tournament function can be used for selecting and the Gaussian function is used for single-point mutation and combination for this generation. Fusion and selection function are considered equal to 500 generations.

\subsection{Using Genetic Algorithms in Polynomial Optimisation}

Heights of polynomials can be useful for interpolation. The most common function to achieve this integration is the general polynomial function shown in Table 3 [37].

Table 3: Polynomial Function for Surface Reconstruction

\begin{tabular}{|c|c|c|c|}
\hline 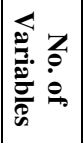 & 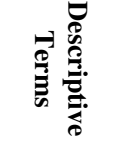 & 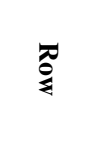 & Formula \\
\hline 1 & Flat & Zero & \multirow{5}{*}{$\begin{array}{l}z=a_{0} \\
+a_{1} x+a_{2} y \\
+a_{3} x^{2}+a_{4} y^{2}+a_{5} x y \\
+a_{6} x^{3}+a_{7} y^{3}+a_{8} x^{2} y+a_{0} x y^{2} \\
+a_{10} x^{4}+a_{11} y^{4}+a_{12} x^{3} y+a_{13} x^{2} y^{2}+a_{14} x y^{3}\end{array}$} \\
\hline 2 & Linear & First & \\
\hline 3 & Quadrati & Second & \\
\hline 4 & Cubic & Third & \\
\hline 5 & Quartic & Fourth & \\
\hline
\end{tabular}

It is clear that the single polynomial function has a special characteristic shape. Using specific terms, unique surface features can be created.

For the actual surface production in a particular model, it is not necessary to use the entire function. The operating system has the responsibility to determine what is used. Only in a few cases it is possible for the user to select which parts of the function to model the particular piece of land that is more relevant.
The first step is to determine the optimal use of polynomial functions in terms of these functions. Shape optimisation of polynomials is related to the geometry and topography of the region. GA is used to evaluate the effect of the presence or absence of various terms in genetic as well as control points that consists of two parts. One of these parts is for the optimisation of the process including control points to find the optimal chromosome. This is referred to as GA Check Points (GACPs). The second part is the independent checkpoint, where the polynomial functions are used to find the most effective functions. For this purpose, a singular binary chromosome in the form of a series of zeros and ones is used. The digit zero indicates non-interference and the digit one indicates the interference. In the process of GA, optimal chromosomes that show the best polynomial term obtained. Coefficients of the terms are determined by the least squares method during this process. In this study, quartic polynomials are examined. For the GA optimisation, firstly the chromosomes must be formed and an initial population created. Each chromosome is made up of variables that are essentially the polynomial coefficients, which is interpreted as gene. Gene 1 represents in the desired term of polynomial and gene 0 represents the interference term in the polynomial. The first algorithm optimisation process consists of an initial population of chromosomes and the coefficients that can be calculated by control points through the least squares method and using checkpoints to determine the remaining residue. So by employing control points, checkpoints and the dependent variable (RMSE), optimal chromosomes are formed. After finishing the optimal processes, the other checkpoints, which have no interference in the process optimisation, the obtained chromosomes will be evaluated. In other words, the process of determining proper coefficients for polynomial with algorithm is used to evaluate the final chromosome, known as Independent Check (ICPs).

\subsection{Using Genetic Algorithms in Optimisation of Inverse Distance Weighting Method}

GA, control and check points can be used to optimise the magnitude of weight and consequently proper weight is achieved. In this article, from the control points and the series of checkpoint (1) as the GACPs can be used to evaluate the strength of optimisation. Finally, the strength obtained from GA is substituted in the IDW equation and as a result the accuracy of the algorithm from the series of checkpoint (2) as the independent checkpoints obtained through the optimisation process with GA (ICPs) are examined and evaluated.

\section{ASSESSMENT OF RESULTS}

IDW interpolation method is used for changing the power of inverse distance and both data sets have been tested and presented in Table 4.

Table 4: Results Obtained from IDW Method

\begin{tabular}{|c|c|c|c|c|}
\hline \multirow{2}{*}{$\begin{array}{c}\text { Inverse } \\
\text { Distance } \\
\text { Power }\end{array}$} & \multicolumn{2}{|c|}{$\begin{array}{c}\text { RMSE from } \\
\text { First Series (m) }\end{array}$} & \multicolumn{2}{c|}{$\begin{array}{c}\text { RMSE from } \\
\text { Second Series (m) }\end{array}$} \\
\cline { 2 - 5 } & CHC(1) & CHC(2) & CHC(1) & CHC(2) \\
\hline 1 & 2.940 & 3.489 & 0.902 & 0.956 \\
\hline 2 & 2.003 & 2.417 & 0.779 & 0.854 \\
\hline 3 & 1.565 & 1.859 & 0.693 & 0.792 \\
\hline
\end{tabular}

As shown in Table 4, the RMSE rate with different powers of inverse distance on two sets of series, the checkpoint values is 
obtained in metres. In both data sets minimum RMSE values are obtain, which is greater to the power of 3 .

In Kriging method, the interpolation of numerous Vary-grams, such as; spherical, linear, exponential, Gaussian, in the position no drift, linear drift and quadratic drift are used and the result is compared in Table 5.

Table 5: Results from Kriging Method

\begin{tabular}{|c|c|c|c|c|c|}
\hline \multirow{2}{*}{$\begin{array}{c}\text { Type of } \\
\text { Vary-gram }\end{array}$} & $\begin{array}{c}\text { Type of } \\
\text { Drift }\end{array}$ & \multicolumn{2}{c|}{$\begin{array}{c}\text { RMSE from } \\
\text { First Series (m) }\end{array}$} & \multicolumn{2}{c|}{$\begin{array}{c}\text { RMSE from } \\
\text { Second Series (m) }\end{array}$} \\
\cline { 2 - 6 } & CHC(1) & CHC(2) & CHC(1) & CHC(2) \\
\hline \multirow{4}{*}{ Spherical } & No Drift & 4.020 & 4.646 & 1.002 & 1.043 \\
\cline { 2 - 6 } & Linear Drift & 2.194 & 2.351 & 0.943 & 0.999 \\
\cline { 2 - 6 } & $\begin{array}{c}\text { Quadratic } \\
\text { Drift }\end{array}$ & 2.193 & 2.350 & 0.932 & 0.989 \\
\hline \multirow{4}{*}{ Exponential } & No Drift & 1.869 & 2.251 & 0.732 & 0.821 \\
\cline { 2 - 6 } & Linear Drift & 1.783 & 1.953 & 0.695 & 0.796 \\
\cline { 2 - 6 } & $\begin{array}{c}\text { Quadratic } \\
\text { Drift }\end{array}$ & 1.782 & 1.952 & 0.690 & 0.793 \\
\cline { 2 - 6 } & No Drift & 1.242 & 1.361 & 0.581 & 0.728 \\
\cline { 2 - 6 } & Linear Drift & 1.309 & 1.391 & 0.574 & 0.725 \\
\cline { 2 - 6 } & $\begin{array}{c}\text { Quadratic } \\
\text { Drift }\end{array}$ & 1.309 & 1.390 & 0.573 & 0.724 \\
\hline \multirow{4}{*}{ Gaussian } & No Drift & 4.020 & 4.646 & 1.002 & 1.043 \\
\cline { 2 - 6 } & Linear Drift & 2.194 & 2.351 & 0.944 & 0.999 \\
\cline { 2 - 6 } & Quadratic & 2.193 & 2.350 & 0.933 & 0.990 \\
\hline
\end{tabular}

As shown in Table 5, the accuracy of the Gaussian and spherical Vary-gram equivalent and the highest accuracy are achieved using linear Vary-gram.

In all cases, linear and quadratic drifts are more accurate compared to no drift, but there is not much difference between quadratic and linear drift. Results of other methods have been shown in Table 6.

Table 6: Results Obtained from other Conventional Interpolation Methods

\begin{tabular}{|c|c|c|c|c|}
\hline \multirow{2}{*}{$\begin{array}{c}\text { Interpolatio } \\
\text { n Method }\end{array}$} & \multicolumn{2}{|c|}{$\begin{array}{c}\text { RMSE from } \\
\text { First Series (m) }\end{array}$} & \multicolumn{2}{c|}{$\begin{array}{c}\text { RMSE from } \\
\text { Second Series (m) }\end{array}$} \\
\cline { 2 - 5 } & CHC(1) & CHC(2) & CHC(1) & CHC(2) \\
\hline $\begin{array}{c}\text { Natural } \\
\text { Neighbour }\end{array}$ & 1.782 & 1.952 & 0.933 & 0.990 \\
\hline $\begin{array}{c}\text { Nearest } \\
\text { Neighbour }\end{array}$ & 1.205 & 1.348 & 0.555 & 0.716 \\
\hline Triangulation & 5.413 & 4.659 & 0.578 & 0.727 \\
\hline $\begin{array}{c}\text { Quartic } \\
\text { Polynomial }\end{array}$ & 1.429 & 1.501 & 0.484 & 0.684 \\
\hline
\end{tabular}

Using GA, control points and checkpoints (1) can be optimised for each set of examined test points that are obtained. The results can be checked against checkpoints (2) where it is independent to the optimisation process. Also a quartic polynomial containing 15 variables has been optimised with respect to GA and the coefficients have been optimised and the proper terms extracted. In this case, the optimisation methods like IDW has a set of control points and a series of checkpoint (1) in the algorithm process used to extract the relevant terms and the results are collected and evaluated against the checkpoint (2). Tables 7 and 8 compare the results that are achieved by using GA with the IDW method and Quartic Polynomial optimisation respectively.

Table 7: Results from IDW Optimisation Method with GA

\begin{tabular}{|c|c|c|c|c|}
\hline & \multicolumn{2}{|c|}{$\begin{array}{c}\text { First Series } \\
\text { Checkpoint }\end{array}$} & \multicolumn{2}{c|}{$\begin{array}{c}\text { Second Series } \\
\text { Checkpoint }\end{array}$} \\
\hline $\begin{array}{c}\text { Indices } \\
\text { Optimisation }\end{array}$ & \multicolumn{2}{|c|}{2.67} & \multicolumn{2}{|c|}{2.964} \\
\hline \multirow{2}{*}{ RMSE (m) } & GACP & ICP & GACP & GACP \\
\cline { 2 - 5 } & 0.662 & 0.978 & 0.466 & 0.684 \\
\hline
\end{tabular}

Table 8: Results of Quartic Polynomial Optimisation with GA

\begin{tabular}{|c|c|c|c|c|c|}
\hline \multirow{2}{*}{$\begin{array}{c}\text { Power of } \\
\text { Polynomials }\end{array}$} & $\begin{array}{c}\text { No. of } \\
\text { Variables }\end{array}$ & \multicolumn{2}{|c|}{$\begin{array}{c}\text { RMSE from } \\
\text { First Series } \\
(\mathbf{m})\end{array}$} & \multicolumn{2}{c|}{$\begin{array}{c}\text { RMSE from } \\
\text { Second Series } \\
(\mathbf{m})\end{array}$} \\
\cline { 3 - 6 } & & GACP & ICP & GACP & GACP \\
\hline 4 & 15 & 0.662 & 0.978 & 0.466 & 0.684 \\
\hline
\end{tabular}

In $\mathrm{NN}$ interpolation, the control points are used for training and a series of checkpoints (1) for validation and for testing/evaluating; checkpoints (2) are used for the perceptron network with a hidden layer of 5 neurons and 10 neurons [38][39], considering the first period size and with momentum $0.7 \mathrm{Ns}$, the following results have been obtained.

Table 9: Results of Interpolation using ANN

\begin{tabular}{|c|c|c|}
\hline \multirow{2}{*}{$\begin{array}{c}\text { No. of Neurons in } \\
\text { Hidden Layer }\end{array}$} & $\begin{array}{c}\text { RMSE from } \\
\text { First Series (m) }\end{array}$ & $\begin{array}{c}\text { RMSE from Second } \\
\text { Series (m) }\end{array}$ \\
\cline { 2 - 3 } & CHC(2) & CHC(2) \\
\hline 5 & 0.708 & 0.711 \\
\hline 10 & 0.815 & 0.705 \\
\hline
\end{tabular}

In order to compare and evaluate different methods of interpolation, the results of the current methods and AI techniques are collected from the RMSE through the series of checkpoint (2). The reason for this is that the AI techniques at the series of checkpoint (1) in the optimisation process of interpolation parameters and for the network validation in GA can be used. Therefore, to ensure that the results of the optimisation process are valid, a series of checkpoint (2) is used as the independent checkpoints. Consequently, the RMSE rates obtained from the conventional interpolation methods and AI techniques are compared with a series of checkpoint (2), which is represented in Figure 2 as a line graph.

As Figure 2 shows, in regards to the width of the checkpoint (1) region with 16 meters altitude, the triangulation method does not produce appropriate results. However, in the checkpoint (2) region that has a wider width compared to checkpoint (1) and only 6 meters altitude, the triangulation method produces better 
results. Thus, due to better triangles obtained in flat regions in regards to the other region, where there are greater changes in altitude, better results are achieved.

In both regions, using Kriging method for interpolation produces better results. It is very important to choose a type of Vary-gram and Kriging method for interpolation. In the first region, AI techniques results in better accuracy rather than conventional methods. However, in the second region, AI techniques produce better accuracy, but little accuracy difference exists in respect to conventional methods. Among the AI techniques within both regions, best accuracy exists within ANN and weighted optimisation based on the inverse distance with respect to GA and their accuracies equivalent.

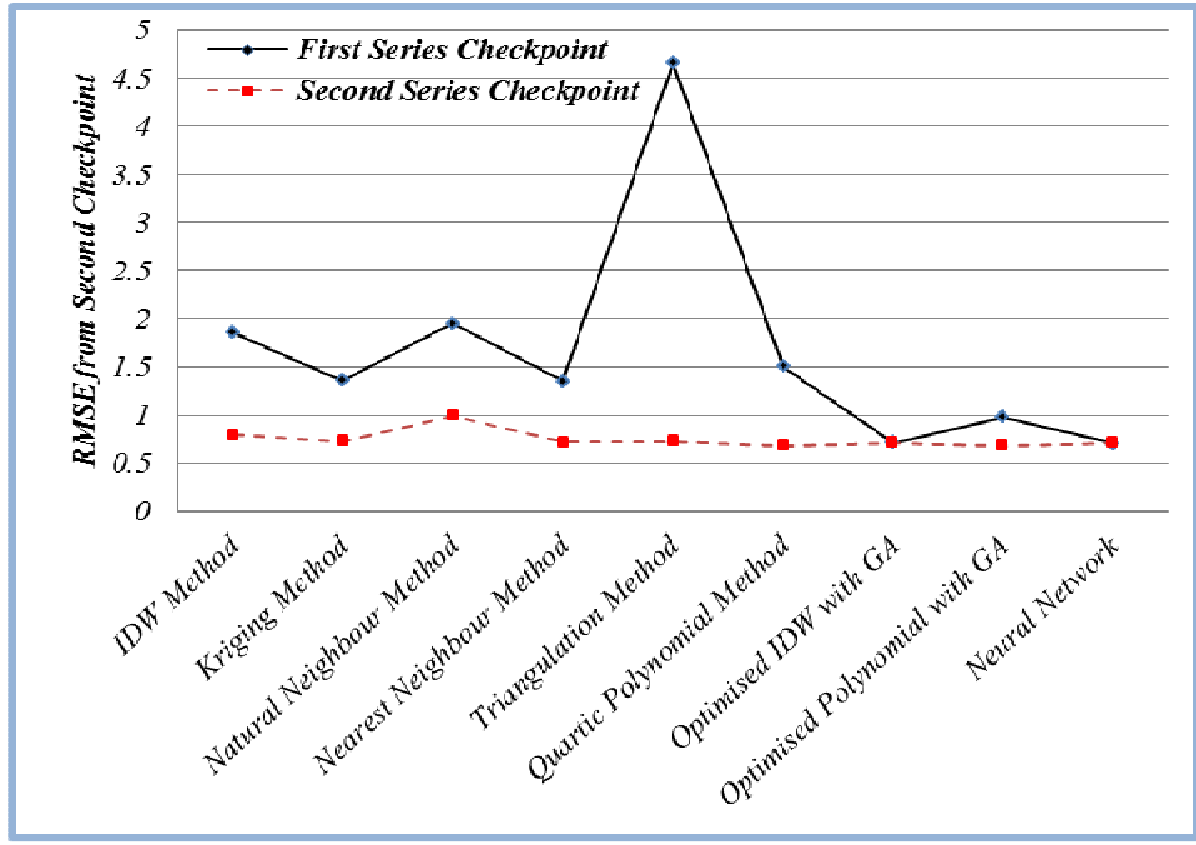

Figure 2: Comparison of Results of Different Interpolation Methods

\section{SUMMARY AND CONCLUSION}

In the evaluation of the results, it is concluded that the use of AI techniques for height interpolation is effective and has a higher level of accuracy compared to conventional methods, especially in areas with high elevation. In order to reveal the best method for polynomial interpolation GA is used and optimal weighting parameters is achieved by IDW method. ANN is able to determine an appropriate weight to indicate the best estimated elevation in unknown altitude regions.

The entire interpolation methods mentioned (conventional and intelligent), the aim is to evaluate the accuracy of interpolation methods. Universal interpolation occurs in the entire surrounding regions and as a result can be suggested for larger regions, which can be divided into smaller regions with respect to altitude changes and in each smaller region obtained universal interpolation can take place. Consequently, the most important problem of distance for both conventional and intelligent interpolation methods can be solved. Also, by using universal interpolation, the time for optimisation in GA and the training time in ANN can be reduced and the difficulty to apply intelligent methods in large regions with numerous sample points can be decreased.

\section{REFERENCES}

[1] Kasser, M. and Egels, Y. 2002, Digital Photogrammetry. CRC Press

[2] Abdul-Rahman, A. and Pilouk, M., 2008, Spatial Data Modelling for 3D GIS. Springer, USA.

[3] Alesheikh, A.A., Soltani, M.J., Nouri, N. and Khalilzadeh, M., 2008, Land Assessment for Flood Spreading Site Selection
Using Geospatial Information System. International Journal of Environmental Science and Technology, 5, 455-462.

[4] Chaplot, V., Darboux, F., Bourennane, H., Leguedois, S., Silvera, N. and Phachomphon, K., 2006, Accuracy of Interpolation Techniques for the Derivation of Digital Elevation Models in Relation to Landform Types and Data Density. Geomorphology, 91, 161-172.

[5] Miller, C. and Laflamme, R. 1958, The digital terrain model - theory and applications, Photogrammetric Engineering, 24:433-442.

[6] Li, Z., Zhu, Q., Gold, C., 2004, Digital Terrain Modeling Principles and Methology, CRC Press.

[7] Heesom, D., and Mahdjobi, L. 2001, Effect of grid resolution and terrain characteristics on data from DTM. J. Comput. Civ. Eng., 15(2), 137-143.

[8] Abdul-Rahman, A., and Pilouk, M., 2008, Spatial Data Modelling for 3D GIS. Springer, USA

[9] Eyvazi, H., Moradi, A., Khoshgoftar, M., 2007, Optimum Determination of Interpolation Model for Using in Geographic Information Systems, Geomatic 86, Tehran, Iran.

[10] Mitas L., and Mitasova H., 1999, Spatial Interpolation, Geographic Information Systems, Principles, techniques, management and applications, pp. 481-492, New York, Wiley.

[11] Li, Z.L., 1990, Sampling Strategy and Accuracy Assessment for Digital Terrain Modelling. Ph.D. thesis, The University of Glasgow, UK. 
[12] Li, Z.L., 1992a, Variation of the accuracy of digital terrain models with sampling interval. Photogrammetric Record, 14(79):113-128.

[13] Hardy, R. L., 1971, Multiquadric equations of topography and other irregular surfaces. J.Geophys. Res. 76 1905-1915.

[14] Hardy, R. L., 1990, Theory and applications of the multiquadric-biharmonic method.20 years of discovery 1968 1988. Computers Math. Applic. 19 (8-9) 163-208.

[15] Larsson, E., Fornberg, B., 2003, Theoretical and Computational Aspects of Multivariate Interpolation With Increasingly Flat Radial Basis Functions. Elisabeth Larsson and Bengt Fornberg. June 2003-035.

[16] Yanalak, M., 2003, Effect of Gridding Method on Digital Terrain Model Profile Data Based on Scattered Data., Journal of Computing in Civil Engineering, 1(58), 58-67.

[17] Amidror, I., 2002, Scattered data interpolation methods for electronic imaging systems: A survey. Journal of Electronic Imaging, 11(2), 157-176.

[18] Rees, W.G., 2000, The Accuracy of Digital Elevation Models Interpolated to Higher Resolutions. Int. J. Remote Sensing, Vol. 21, No. 1, 7- 20.

[19] Yang, C.S., Kao, S.P., Lee, F.B., Hung, P.S., 2004, "Twelve Different Interpolation Methods: A Case Study." ISPRS International Symposium, Istanbul-Turkey.

[20] Hertz, J., Krogh, A. Palmer.R.G., 1991, Introduction to the Theory of Neural Computation. Addison-Wesley Publishing Company, Redwood City, CA.

[21] Foody, G.M., McCulloch, M.B., and Yates, W.B., 1995, Classification of remotely sensed data by an artificial neural network: issues related to training data characteristics. Photogrammetric Engineering \& Remote Sensing, pvol. 61, No. 4, pp: 391-401.

[22] Picton, P., 2000, Neural Networks. Palgrave, Macmillan.

[23] Mokhtarzade, M., Valadan Zoej, M.J., 2007, Road detection from high-resolution satellite images using artificial neural networks, International Journal of Applied Earth Observation and Geoinformation 9, pp. 32-40.

[24] Wiszniewski, A., 1983, Accurate Fault Impedance Locating Algorithm. IEEE Proceedings C, Generation, Tranmission, Distribution, 6, 311-314.

[25] Holland, J.H. et. Al., 1989, Induction: Processes of Inference, Learning, and Discovery. MIT Press.

[26] Freisleben, B. and Merz, P., 1996, New local search operators for traveling salesman problem. 4th International Conference on Parallel Problem Solving from Nature, PPSN IV, Berlin Heidelberg New York, vol. 1141 of LNCS, pp. 2226, Springer.

[27] Sheta, A. and Turabieh, H., 2006, A comparison between genetic algorithms and sequential quadratic programming in solving constrained optimization problems. ICGST International Journal on Artificial Intelligence and Machine Learning (AIML), Vol. 6, No. 1, pp. 67-74.

[28] Sivanandam, S.N. and Deepa S.N., 2010, Introduction to Genetic Algorithms, Springer.Berlin Heidelberg.

[29] Ravagnani, M.A.S.S. Silva, A.P. Constantino Arroyo, P.A., 2005, Heat exchanger network synthesis and optimisation using genetic algorithm Applied Thermal Engineering Vol. 25, No. 7, pp. 1223-1217.

[30] Haupt, R.L. and Haupt, S.E., 2004, Practical Genetic Algorithm. 2nd Edition whit CD, John Wiley \& Sons.

[31] Lu, G.Y. and Wong, D.W., 2008, An Adaptive Inversedistance Weighting Spatia Interpolation Technique. Computers \& Geosciences, 34, 1044- 1055.

[32] Matheron, G., 1963, Principles of Geostatistics. Economic Geology, 58, 1246-1266.

[33] Krige, D.G., 1951, A Statistical Approach to Some Mine Valuations and Allied Problems at the Witwatersrand, Master's thesis of the University of Witwatersrand.

[34] Cressie, N., 1988, Spatial Prediction and Ordinary Kriging. Mathematical Geology, 20, 405-421.

[35] Sibson, R. 1980, A Vector Identity for the Dirichlet Tesselation, Math. Proc. Cambridge Phil. Soc., v. 87, p. 151155.

[36] Sibson, R. (1981), A Brief Description of Natural Neighbor Interpolation, Interpreting Multivariate Data, V. Barnett editor, John Wiley and Sons, New York, p. 21-36.

[37] Petrie, G. and Kennie, T. (Eds.), 1990, Terrain Modelling in Surveying and Civil Engineering. Whittles Publishing, Caithness, England.

[38] Saati, M., Amini, J., Sadeghian, S., 2008, Generation of orthoimage from high resolution DEM and high resolution image, Scientia Iranica, Vol. 4, No. 4.

[39] Karabork, H., Baykan, O.K., Altuntas, C. and Yildz, F., 2008, Estimation of Unknown Height with Artificial Neural Network on Digital Terrain Model. The International Archives of the Photogrammetry, Remote Sensing and Spatial Information Science. XXXVII, 115-118.

[40] Florinsky, I., 2011, Digital Terrain Analysis in Soil Science and Geology, Academic Press; 1st Edition.

[41] Mesnard, L. de, 2013, Pollution models and inverse distance weighting: Some critical remarks, Computers \& Geosciences, Vol. 52, pp. 459-469.

[42] Li, J., Heap, A., D., 2011, A review of comparative studies of spatial interpolation methods in environmental sciences: Performance and impact factors, Ecological Informatics,Vol. 6, Issues 3-4, pp. 228-241.

[43]Wagnera, P. D., Fienera, P., Wilkena, F., Kumarc., S., Schneidera, K., 2012, Comparison and evaluation of spatial interpolation schemes for daily rainfall in data scarce regions, Journal of Hydrology, Vol., 464-465, pp. 388-400.

[44]Lu, G., Y. and Wong, D., W., 2008, An adaptive inversedistance weighting spatial interpolation technique, Computers \& Geosciences Journal, Vol. 34, Issue 9, pp. 1044-1055.

[45] Zhong, D., Liu, J., Li, M., Hao, C., 2008, NURBS reconstruction of digital terrain for hydropower engineering based on TIN model, Progress in Natural Science, Vol. 18, Issue 11, 10, pp. 1409-1415 